\title{
Freeze-drying of a mixture of bacterium and yeast for application in postharvest control of pathogenic fungi
}

\author{
Leonardo G. Navarta ${ }^{1} \cdot$ Juan Calvo ${ }^{1} \cdot$ Paola Posetto ${ }^{1} \cdot$ Delia Benuzzi $^{1} \cdot$ María I. Sanz ${ }^{1,2}$ (D)
}

Received: 5 December 2019 / Accepted: 10 June 2020 / Published online: 15 June 2020

(c) Springer Nature Switzerland AG 2020

\begin{abstract}
The use of formulations based on microorganisms for the control of phytopathogenic fungi increases continuously, due to the risk of pesticide residues in food and the negative impact on the environment. Herein we present the obtaining by lyophilization of a dry mixed formulation containing two biological control agents, the bacterium Kosakonia radicincitans and the yeast Cryptococcus laurentii for the biocontrol of Botrytis cinerea and Penicillium expansum on stored apple fruit. For the formulation is used a complex cryoprotectant, that consists of $10 \%$ skimmed nonfat milk, $0.5 \%$ yeast extract, and $1 \%$ glucose. Two pre-freezing temperatures and different concentrations of the cryoprotectant are tested. Survival and antagonistic capacity of the formulation are compared with the mix of the bacterium and the yeast separately lyophilized. Results show higher antagonism of the mixture against $B$. cinerea and $P$. expansum than each microorganism separately. Concerning survival, it decreases significantly for both microorganisms in comparison when they are lyophilized individually. The bacterium seems the most affected by joint lyophilization. In the lyophilized mixture, the viability of the microorganisms is $38.8 \%$ for $\mathrm{K}$. radicincitans and $44.7 \%$ C. laurentii. While for microorganisms that are lyophilized individually, the viability is $92.5 \%$ for the bacterium and $81.9 \%$ for the yeast. The change in concentration of complex cryoprotectant improves survival. K. radicincitans reaches the highest survival value (53.9\%), but the survival of $C$. laurentii is not altered. The antagonistic activity of the lyophilized mixture also improves. The incidence of disease for $P$. expansum decreases to $26 \%$ and for $B$. cinerea to $16 \%$. The formulation developed could have practical advantages for its commercialization and application since the two biological control agents are present in a single product.
\end{abstract}

Keywords Freeze-dry mixture · Kosakonia radicincitans · Cryptococcus laurentii · Biocontrol · Penicillium expansum · Botrytis cinerea

\section{Introduction}

At present, the trade-in fresh fruit is highly appreciated for the high nutritional value of these products [5]. Countries like Argentina provide fruit to meet needs over the year at the internal market as well as exports to other continents, which requires long-term forced storage [26]. The exportation complex of apples and pears are potential and especially considerable for account $1.1 \%$ of exports from total Argentine foreign trade [9], and organic exports are estimated to rise in the next few years on the expectation of a continuing price over regular prices [26].

Losses in postharvest steps can reach a range of up to $50 \%$ of stored fruits, and fungal diseases are the leading cause of injuries of fresh fruits and vegetables at this period $[17,22]$. The increase in the governmental control of the presence of chemical fungicide residues in the fruit trade, as well as the adaptation of the pathogenic

$\triangle$ María I. Sanz, msanz@unsl.edu.ar| ${ }^{1}$ Área de Tecnología Química Y Biotecnología, Departamento de Química, Facultad de Química, Bioquímica y Farmacia, Universidad Nacional de San Luis, Ejercito de los Andes 950, San Luis, Argentina. ${ }^{2}$ Instituto de Química San Luis, INQUISAL, CONICET-Universidad Nacional de San Luis, San Luis, Argentina. 
microorganisms to these chemicals, suggest the need to develop alternative methodologies non-pathogenic to plants or humans, to avoid the rot of stored products [17, $21,25,28]$.

The use of biopesticides containing antagonistic microorganisms is a likely strategy, and the literature shows the successful use of bacteria and yeasts as biological control agents (BCAs) against pathogens $[3,11,16,19,27]$. A critical point in the application of biological control is the preparation of a formulation in which the active ingredient (microorganism) may be maintained stable, effective, and be safely handled.

Generally, a formulation contains the antagonistic microorganism, a carrier that is an inert material, and nutrients and compounds that improve the survival of the antagonist cells or help protect them from environmental changes under commercial conditions and significantly increasing the useful life of the product. After selecting a microorganism as a BCA, the second step is to study preservation ways. Some alternatives are storage at low temperatures (freezing or refrigeration) and lyophilization techniques that are often applied to maintain the viability of cultures. Even though the lyophilization is an easy way to keep a reasonable number of viable cells, this preservation process can cause damage leading to the death of microorganisms or deterioration of its antagonistic quality. These consequences can be minimized by optimizing freeze-drying conditions and using cryoprotective agents [16].

Although many authors have reported the successful use of mixtures of antagonistic microorganisms for the control of different phytopathogens [1, 3, 4, 6, 18, 23], there are no many current reports of lyophilized formulations based on mixtures of BCA. The available data on freeze-drying involves mainly pure cultures, but there is no information about the freeze-drying of mixed cultures for biocontrol of postharvest diseases.

In previous work, we demonstrated that the use of a mixture of bacterium and yeast resulted in a mix with a strong antagonism against Botrytis cinerea and Penicillium expansum [3]. We also developed lyophilized formulations with Cryptococcus laurentii [16]. Lately, we have isolated and tested as BCA, the bacterium Kosakonia radicincitans [12], which in combination with C. laurentii, was effective in controlling $P$. expansum in apple (unpublished results). To date, we have not found reports about formulations containing $K$. radicincitans or mixtures of this bacterium with other BCAs.

This work presents the selection of cryoprotectant and the pre-lyophilization conditions for the freeze-drying of $K$. radicincitans and C. laurentii and its mixture. The antagonistic activity of lyophilized mixture against $B$. cinerea and $P$. expansum is tested in apples in cold storage. Population dynamics are evaluated in apple wounds to explain the antagonistic activity, and the differences from a mixture of separately lyophilized microorganisms and the lyophilized mixture are described.

\section{Materials and methods}

\subsection{Microorganisms}

Cryptococcus laurentii isolated from apple skin was identified biochemically with API 20 C AUX system (bioMérioux, France). For the molecular identification, Macrogen (Korea) amplified the $26 \mathrm{~S}$ rRNA sequence using the primers LROR 5' (ACC CGC TGA ACT TAA GC) 3' and LR7 5' (TAC TAC CAC CAA GAT CT) 3'.

Kosakonia radicincitans was isolated from the apples surface, were used API $20 \mathrm{E}$ and API 50 CHE systems (bioMérioux, France) for metabolic profile determination. For molecular identification, Macrogen (Korea) amplified the 16S rRNA sequence using the following bacterial-specific primer set: 785F 5' (GGA TTA GAT ACC CTG GTA) 3' and 907R 5' (CCG TCA ATT CMT TTR AGT TT) 3'.

Botrytis cinerea and Penicillium expansum were used in the control assays. B. cinerea was ceded to us by the National Institute of Agricultural Technology (INTA, Mendoza, Argentina). P. expansum was bought in Mycological Reference Center (CEREMIC, Rosario, Argentina).

\subsection{Culture media and growth conditions}

The phytopathogenic fungi were cultured on Potato Dextrose Agar (PDA, Sigma Chemical Co, St. Louis, MO). For conidial production, $B$. cinerea was cultured on PDA at 20-25 ${ }^{\circ} \mathrm{C}$; after the mycelium appeared, cultures were kept at $15^{\circ} \mathrm{C}$ for inducing sporulation. Conidia of $P$. expansum were obtained from 7 days old in PDA cultures grown at $20-25{ }^{\circ} \mathrm{C}$. The conidia of the phytopathogens were suspending in $10 \mathrm{~mL}$ of sterile distilled water containing $0.05 \%(\mathrm{v} / \mathrm{v})$ Tween 80 . The suspension concentration was determined using a Neubauer chamber and adjusted with sterile distilled water to $1 \times 10^{5}$ conidia $\mathrm{mL}^{-1}$.

C. laurentii and $K$. radicincitans were grown in YGA (yeast extract $5 \mathrm{gL}^{-1}$, glucose $10 \mathrm{gL}^{-1}$, and agar $20 \mathrm{gL}^{-1}$ ) and stored at $4{ }^{\circ} \mathrm{C}$. For biomass production, these microorganisms were cultured in YGM (yeast extract $5 \mathrm{gL}^{-1}$ and glucose $10 \mathrm{gL}^{-1}$ ). The cultures were made in $1 \mathrm{~L}$ Erlenmeyer flasks with baffles containing $250 \mathrm{~mL}$ of the medium at $28^{\circ} \mathrm{C}$ on a rotary shaker ( 2,5 eccentricity, $\left.140 \mathrm{rpm}\right)$. Cells were harvested at the beginning of the stationary phase by centrifugation at $8315 \mathrm{~g}$ for $10 \mathrm{~min}$ in a Sorvall SS-3 (DuPont Instruments, Newton, CT). The growth medium was decanted, and the cell pellet was suspended in 15 
$\mathrm{mL}$ of $0.05 \mathrm{~mol} \mathrm{~L}^{-1}$ potassium phosphate buffer (PB), $\mathrm{pH}$ 6.5 , and centrifuged again. Finally, cells were prepared for lyophilization.

\subsection{Kosakonia radicincitans freeze-drying: Selection of cryoprotectant and conditions pre-lyophilization.}

Different cryoprotectants were tested for $K$. radicincitans. A primary protecting medium was formulated with $10 \%$ $(\mathrm{w} / \mathrm{V})$ of powdered skimmed nonfat milk (Molico Sveltesse, Nestle, Buenos Aires, Argentina) in deionized water (SM10). To this basic cryoprotectant were added different compounds in a concentration of $10 \%(\mathrm{w} / \mathrm{v})$. The additives were sugars (glucose, fructose, lactose, sucrose, trehalose) and polyols (glycerol, inositol). Furthermore, a protecting mixture was assayed (SMYG), consisted of skimmed nonfat milk (SM) $10 \%$, yeast extract (YE) $0.5 \%$, and glucose (G) $1 \%$. Protecting solutions were sterilized in an autoclave. After cell harvest, the resulting dough was suspended in the protecting medium, and the initial cell concentration $\left(\mathrm{N}_{0}\right)$ of each suspension was adjusted to $1 \times 10^{9} \mathrm{CFU} \cdot \mathrm{mL}^{-1}$ by the standard count method on the YGA plate. For each protecting medium to assay, three autoclaved vials were filled with $5 \mathrm{~mL}$ of sample and placed at $-20^{\circ} \mathrm{C}$ and -70 ${ }^{\circ} \mathrm{C}$ overnight.

\subsection{Cryptococcus laurentii freeze-drying}

Preparation of $C$. laurentii cells before freeze-drying and cryoprotectant used were according to the methodology previously reported by Navarta et al. [16]. As cryoprotectant was used SMYG and before lyophilization, the cells suspended in SMYG and were placed at $-70^{\circ} \mathrm{C}$ overnight. The initial cell concentration $\left(\mathrm{N}_{0}\right)$ of each suspension was adjusted to $1 \times 10^{9} \mathrm{CFU} . \mathrm{mL}^{-1}$ by the standard count method on the YGA plate.

\subsection{Lyophilization procedure}

For each antagonistic microorganism, ten sterile vials were prepared with $5 \mathrm{~mL}$ of suspension and cooled to $-70{ }^{\circ} \mathrm{C}$ overnight, as was explained before. The vials were then placed in a lyophilizer chamber (Labconco7740030, Labconco Corp., Kansas City, MO, USA) at $-45^{\circ} \mathrm{C}$ and 0.05 mbar for $12 \mathrm{~h}$. The freeze-dried samples were rehydrated at the original volume $(5 \mathrm{~mL})$ with the protectant medium. They were left at room temperature for $20 \mathrm{~min}$. The number of CFU per milliliter was determined by counting on YGA plates. The number of viable cells (survival level) was calculated by comparing them before $\left(\mathrm{N}_{0}\right)$ and after $\left(\mathrm{N}_{\mathrm{f}}\right)$ of freeze-drying and rehydration processes. This determination was repeated twice.
$\%$ Viability $=\left(\mathrm{N}_{\mathrm{f}} / \mathrm{N}_{\mathrm{o}}\right) \times 100$. The value range was from 0 (not any cell viable) to 100 (total survival).

\subsection{Obtention of the lyophilized mixture (LM)}

\subsubsection{Effect of freezing temperature on the viability of the lyophilized mixture (LM)}

Before lyophilization $K$. radicincitans and C. laurentii were mixed in 1:1 proportion (vol/vol) then the suspension was put in the vials. To checking the effect of freezing temperature before freeze-drying, the vials were stored at $-20^{\circ} \mathrm{C}$ or $-70^{\circ} \mathrm{C}$, in a static state for $24 \mathrm{~h}$. After this time, samples were lyophilized, and viability was determined as it was previously described.

\subsubsection{Effect of variation of SMYG composition on the viability of the microorganisms in the lyophilized mixture (LM)}

The effect of different compositions of SMYG on the viability of the microorganisms in the lyophilized mixture was studied. SMYG was formulated as follow: (a) SM 5\%, YE $0.25 \%$, G 0.5\% (SMYG 5); (b) SM 10\%, YE 0.5\%, G 1\% (SMYG 10); (c) SM 15\%, YE 0.75\%, G 1.5\% (SMYG 15) and (d) SM 20\%, YE 1\%, G 2\% (SMYG 20). The methodology of cell preparation, freeze-drying, and rehydration was the same as before.

\subsection{Biocontrol of $B$. cinerea and $P$. expansum on apples in cold storage by the mixture lyophilized (LM)}

For biocontrol tests, the lyophilized mixture (LM) was hydrated with SMYG medium before use. K. radicincitans and $C$. laurentii, lyophilized separately, were mixed in three proportions (vol/vol):1:1 (Mix A); 2:1 (Mix B); and 1:2 (Mix C), and were used as controls. In all cases was used SMYG medium for hydratation.

The antagonistic activity of the lyophilized mixture (LM) against $B$. cinerea or $P$. expansum was tested on coldstored apples. Red Delicious apples free of wounds and decay were perfectly washed and dried in the air. The fruits were then punctured, making a wound $(2 \times 2 \times 2 \mathrm{~mm})$ in two places over the central section. In each wound was placed $20 \mu$ of suspension $\left(1 \times 10^{6} \mathrm{CFU} \mathrm{mL}^{-1}\right)$ of $L M, K$. radicincitans, $C$. laurentii, or their mixtures. Sterile distilled water was used as a negative control. After three hours of waiting, the treated wounds were inoculated with 20 $\mu \mathrm{l}$ of $B$. cinerea or $P$. expansum conidia $\left(1 \times 10^{5} \mathrm{CFU} \mathrm{mL}^{-1}\right)$. The apples were stored for 40 days at $4{ }^{\circ} \mathrm{C}$ and $90 \pm 5 \% \mathrm{RH}$. Antagonist capacity was recorded as Disease Incidence (DI $\%)$, percentage of wounds that develop the disease, and 
calculated from lesion as DI \% = (number of wounds that develop disease/total number of wounds treated) $\times 100$. El value may range from $0 \%$ (total effectiveness) to $100 \%$ (no antagonist effect). Each treatment was replicated three times on groups of twenty apples.

\subsection{Population dynamics}

Population dynamics were also evaluated on Red Delicious apples. Following the methodology reported by Calvo et al. [3], apples were wounded in the equatorial zone (five wounds per fruit, $3 \mathrm{~mm}$ diameter $\times 3 \mathrm{~mm}$ depth), and 20 $\mu \mathrm{l}$ of the suspension $\left(1 \times 10^{6} \mathrm{CFU} \mathrm{mL}^{-1}\right)$ of $\mathrm{BCA}$ was placed on each wound. The apples were incubated at $4{ }^{\circ} \mathrm{C}$ and $90 \pm 5 \%$ RH. Samples were taken at 0 (prior to storage), 3 , $6,9,12,15,20,25,30$, and 40 days. The wounded tissue was removed using a cork borer ( $6 \mathrm{~mm}$ internal diameter), suspended in $50 \mathrm{~mL}$ of sterile distilled water, and shaken on a rotatory shaker for $20 \mathrm{~min}$ at $240 \mathrm{rpm}$. Serial dilutions of the washings were made and plated on YGA plates. The colonies were counted after $48 \mathrm{~h}$ of incubation at $30^{\circ} \mathrm{C}$. There were three replicates of three fruit per treatment, and the experiment was repeated twice. The lyophilized mixture (LM) was evaluated and compared with lyophilized cells of $C$. laurentii or $K$. radicincitans and their 1:1 mixture.

\subsection{Data analysis}

The data were analyzed by analysis of variance (ANOVA) using Statistical Software InfoStat, 2008. The statistically significant differences $(p<0.05)$ were analyzed by multiple comparison test of Tukey.

\section{Results}

\subsection{Kosakonia radicincitans freeze-drying: selection of cryoprotectant and conditions pre-lyophilization.}

The viability of $K$. radicincitans after freeze-drying was significantly different, depending on the protectant used (Fig. 1). SMYG medium was the best cryoprotectant. With this medium, cell viability reached $95.6 \%$, while cell viability in deionized water (Negative control) only reached $1.7 \%$. The other protectants tested were less effective. Mixtures of SM10 with disaccharides (sucrose, lactose, and trehalose) were less effective than combinations with monosaccharides (glucose and fructose). Among the monosaccharides, glucose had the best performance, giving cell viabilities at $38.5 \%$. When glycerol and inositol were mixed with SM10, the cell viabilities were low, and

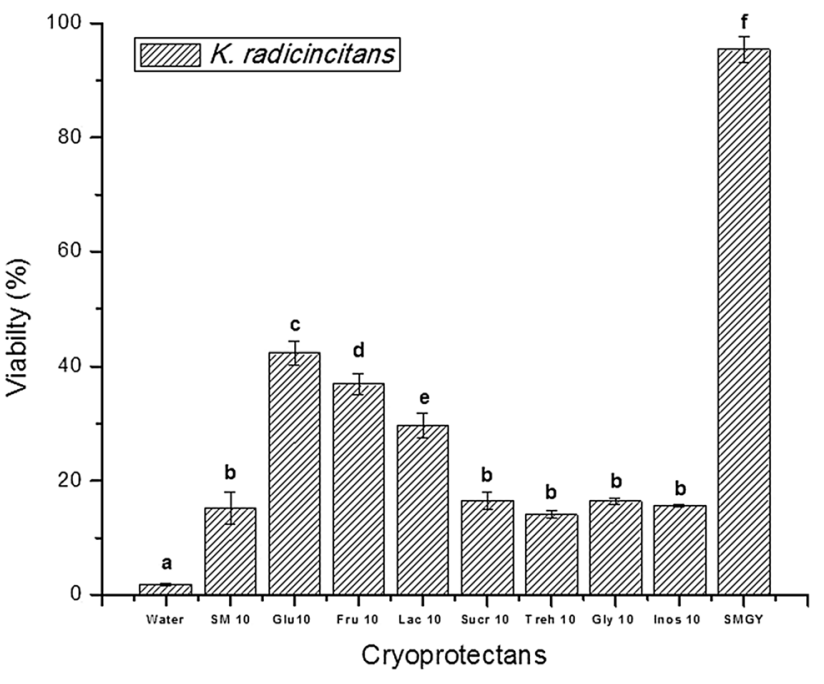

Fig.1 Effect of different cryoprotectants on the viability of $K$. radicincitans after lyophilization. For each protecting medium assayed, three autoclaved vials were filled with $5 \mathrm{~mL}$ of sample and placed at $-70{ }^{\circ} \mathrm{C}$ overnight. Measurements with the same letter do not show significant differences $(p<0.05)$

there was no significant difference from the SM10 alone. On the other hand, results obtained in the treatments prelyophilization at two different temperatures showed a significant difference. When $K$. radicincitans cells were frozen quickly $\left(-70^{\circ} \mathrm{C}\right)$, viability after freeze-drying reached $99 \%$, while when the cells were frozen slow $\left(-20^{\circ} \mathrm{C}\right)$, the viability was $64 \%$.

\subsection{Lyophilization of the mixture of BCAs and effect of pre-lyophilization treatments in survival}

Taking into account that the SMYG medium also gives the best results for the lyophilization of C. laurentii (81.91\% viability) according to Navarta et al. [16], the freeze-drying assays of the BCAs mixture were carried out with SMYG as a protectant.

The viability of microbial cells lyophilized in the mixture was studied and compared with the survival of microbial cells freeze-drying separately. Also, it was considered the effect of freeze temperature before lyophilization. Results of the viability of the BCAs cells after their lyophilization in a mixture previously pre-frozen at $-20^{\circ} \mathrm{C}$ or $-70^{\circ} \mathrm{C}$ are shown in Fig. 2. In the lyophilized mixture (LM), the viability of the microorganisms was $38.8 \%$ for $K$. radicincitans and $44.7 \%$ C. laurentii (significant differences $p<0.05$ ). While for microorganisms that were lyophilized individually with the previous pre-frozen at $-70^{\circ} \mathrm{C}$, the viability was $92.5 \%$ for $K$. radicincitans and $81.9 \%$ for C. laurentii (Fig. 2). In these assays, it can also be seen that the fast freezing before the lyophilization $\left(-70^{\circ} \mathrm{C}\right)$ was more effective than freezing to $-20^{\circ} \mathrm{C}$ (significant difference $p<0.05$ ), 


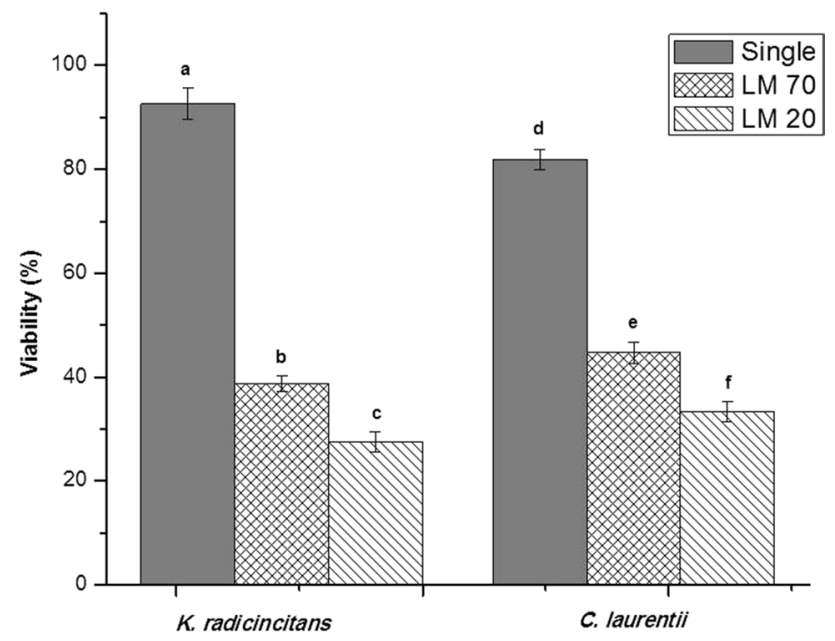

Fig.2 Effect of pre-lyophilization treatments on the viability of BCAs in the lyophilized mixture (LM). The mix of $K$. radicincitans and C. laurentii (1:1) was pre-frozen at $-20^{\circ} \mathrm{C}$ or $-70{ }^{\circ} \mathrm{C}$ before freezedrying. Controls consisted of $K$. radicincitans and $C$. laurentii lyophilized separately, previous pre-frozen to $-70^{\circ} \mathrm{C}$. Measurements with the same letter do not show significant differences $(p<0.05)$

but did not improve the viability of $K$. radicincitans and $C$. laurentii in comparison with the lyophilization separately.

\subsection{Effect of different concentrations of the cryoprotectant on the viability of the lyophilized mixture (LM)}

The effect of different concentrations of the SMYG cryoprotectant on the viability of cells lyophilized in a mixture is shown in Fig. 3. It was observed a significant increase in the survival of $K$. radicincitans between SMYG 5, 10 and 15 but there were no significant differences between SMYG 15 and 20. At these concentrations, K. radicincitans achieved the highest survival value (53.9\%). In respect to C. laurentii, survival did not show significant differences at any of the different concentrations of SMYG used in the trial.

\subsection{Determination of the antagonistic activity of freeze-dried microbial cells against $B$. cinerea and $P$. expansum on apples in cold storage}

Figure 4 shows the antagonistic activity (measured as the incidence of disease, DI \%) of freeze-dried microbial mixture against $B$. cinerea and $P$. expansum on apples in cold storage $\left(4^{\circ} \mathrm{C}\right)$. In these tests, $K$. radicincitans and C. laurentii, previously lyophilized separately and mixed in different proportions (Mixture A, 1:1; Mixture B, 2:1, and Mixture $C, 1: 2$ ), were used as control. These mixtures were compared with the lyophilized mixture (LM) and with each BCA separately. Antagonist mixtures were

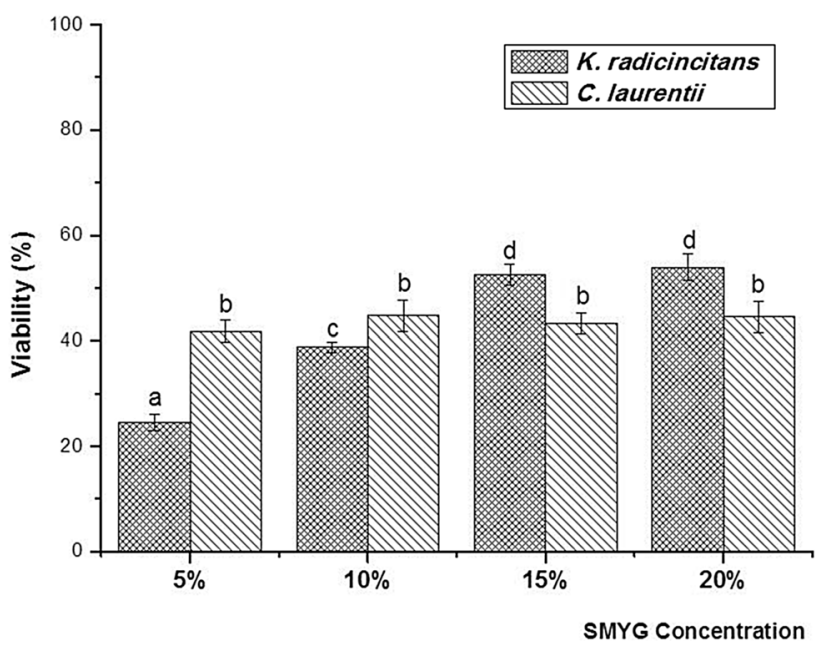

Fig.3 Effect of variation of SMYG composition on the viability of $K$. radicincitans and $C$. laurentii in the lyophilized mixture (LM). SMYG was formulated as follow: a SM 5\%, YE 0.25\%, G 0.5\% (SMYG 5); b SM 10\%, YE 0.5\%, G 1\% (SMYG 10); c SM 15\%, YE 0.75\%, G $1.5 \%$ (SMYG 15) and d SM 20\%, YE 1\%, G 2\% (SMYG 20). Measurements designated with the same letter are not significantly different $(p<0.05)$

more effective in all cases than each antagonist alone. However, the lyophilized mixture (LM) using SMYG 10 as the cryoprotectant was less effective. The incidence of $P$. expansum disease reached $45 \%$, while the $B$. cinerea

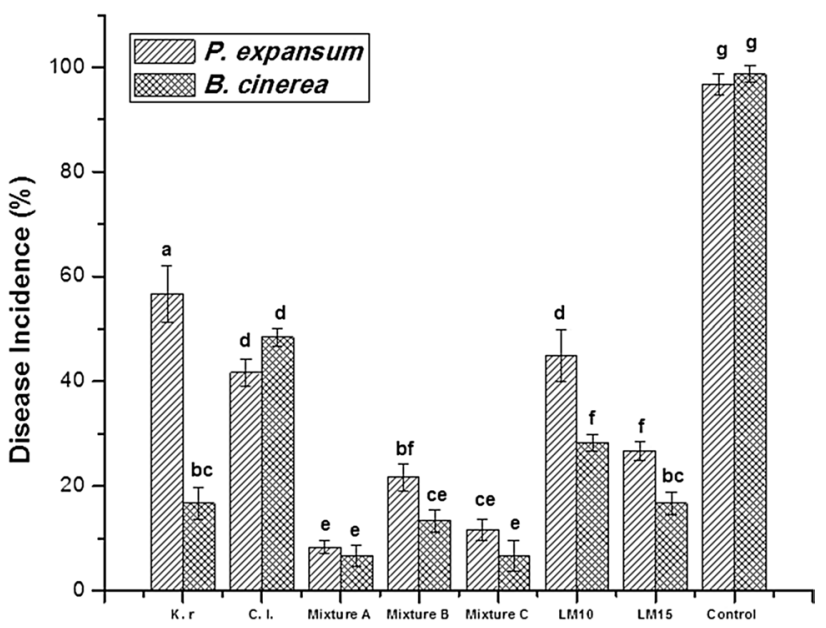

Fig.4 Control of B. cinerea and P. expansum on Red Delicious apples in cold storage by mixtures of lyophilized antagonists or mixture lyophilized (LM). Apple wounds were treated with: a Formulations containing K. radicincitans (K.r.), C. laurentii (C.I.), b Mixtures (vol/ vol) of K.radicincitans and C. laurentii lyophilized separately (Mixture A, 1:1; Mixture B, 2:1; and Mixture C 1:2), c Lyophilized Mixture,(1:1) using as cryoprotectant SMYG 10\% (LM 10) and SMYG $15 \%$ (LM 15), d Sterile distilled water as a control. After the inoculation with the phytopathogen, apples were stored for 40 days at 4 ${ }^{\circ} \mathrm{C}$ and $90 \pm 5 \% \mathrm{RH}$. Measurements of disease incidence (\%) designated with the same letter are not significantly different $(p<0.05)$ 
disease was $30 \%$. The antagonism of LM improved when the concentration of cryoprotectant used in the lyophilization was modified (SMYG 15). In this case, the incidence of $P$. expansum disease decreased to $26 \%$ and $B$. cinerea to $16 \%$, and there were no significant differences with the Mixture B (2:1) of separately lyophilized BCAs.

\subsection{Population dynamics}

The dynamics of the populations were different when the mixture of the lyophilized microorganisms was made at the time of the inoculum (Fig. 5a) or when the lyophilized mixture (LM) was put in the apple wounds (Fig. 5b). Furthermore, both were different than when each lyophilized microorganism was inoculated separately as a control. The presence of $C$. laurentii affected the growth of $K$. radicincitans since this bacterium did not reach the same concentration as when it was inoculated alone in the wounds; instead, the yeast did not seem affected by the presence of the bacteria. In the mixture made at inoculation (Fig. 5a), both microorganisms grew similarly until the third day. The bacterial population decreased, and $C$. laurentii reached its maximum level between 10 and 15 days and remained in the wound at that concentration until the end of the test. However, when the lyophilized mixture (LM) was inoculated (Fig. 5b), it was possible to observe a lag period in the growth of C. laurentii until the third day. At this time, the bacterial population was significantly higher than the yeast population.

\section{Discussion}

An underused strategy to improve biological control is the mixing of yeasts and bacteria. In our experience, a mixture of bacteria and yeasts such as Rahnella aquatilis and Rhodotorula glutinis proved to be very effective against two important postharvest diseases. As was reported by Calvo et al. [3], Penicillium expansum and Botrytis cinerea were controlled by the mixture. The capacity of $C$. laurentii and $K$. radicincitans to control postharvest disease was demonstrated in previous works by Navarta et al. [16] and Lambrese et al. [12].

By using mixtures, it was shown that the combination of two microorganisms with different nutritional requirements, different ecological niches, and different antagonistic abilities improved the control of different phytopathogenic molds $[3,4,7,18,24]$. However, no formulation of this type has been developed to date.

In this work, a dry formulation was developed lyophilizing a mixture of the biological control agents $K$. radicincitans and $C$. laurentii. Survival and antagonistic capacity of the formulation obtained were compared with the mix of the bacterium and the yeast individually lyophilized. Concerning survival, a surprising result was that although SMYG was the best cryoprotectant for both microorganisms, survival decreased significantly for both in comparison when the microorganisms were lyophilized individually. Of the two, the bacterium seemed the most affected by joint lyophilization. Regarding the antagonistic capacity of the mixture of microorganisms, the results showed that it was higher than that of the antagonists separately. $K$.

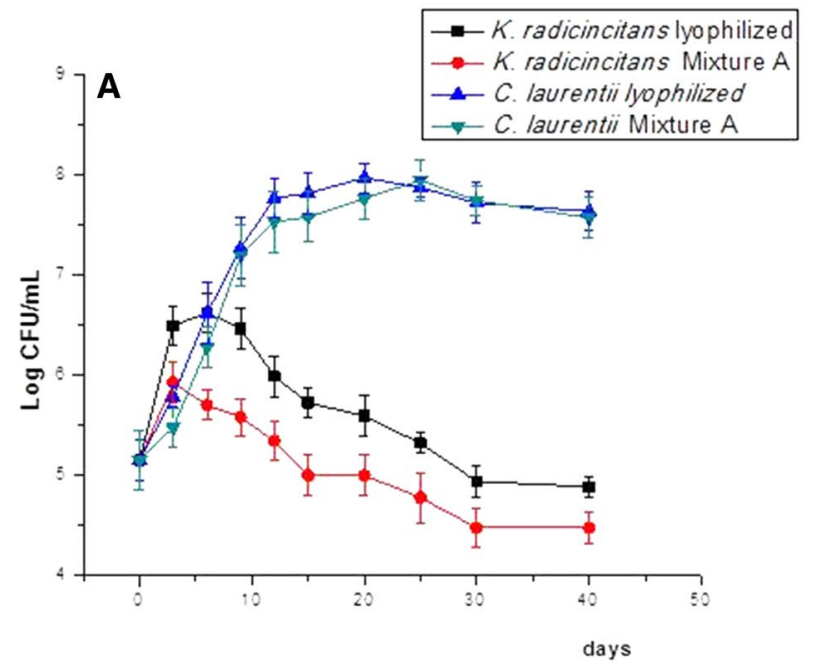

Fig.5 Populations dynamics of a lyophilized microorganisms mixed (Mixture $A, 1: 1$ ) at inoculation time or $\mathbf{b}$ Lyophilized mixture (LM). Population dynamics were evaluated on Red Delicious apples. After

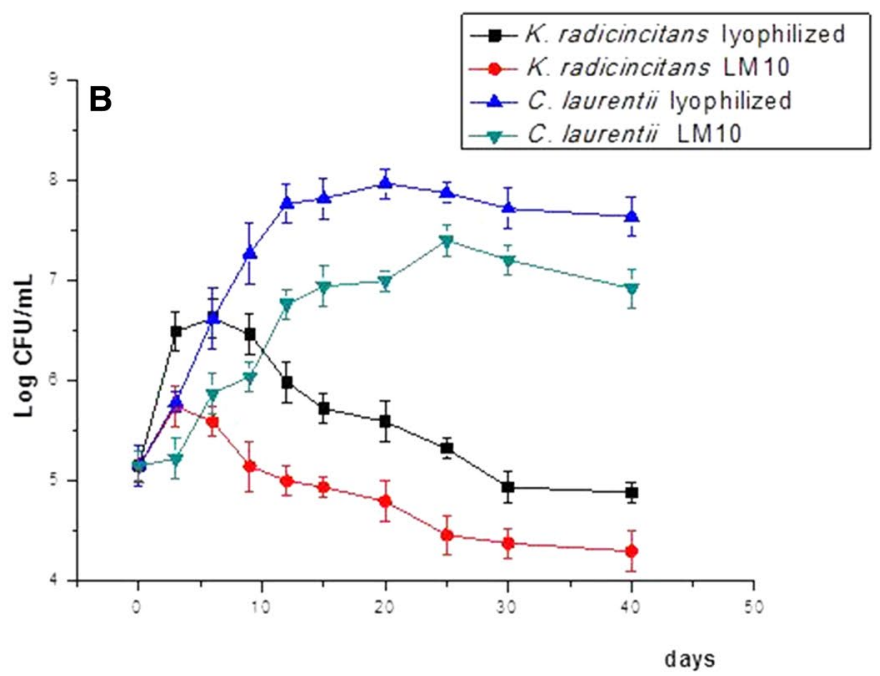

inoculation, apples were incubated for 40 days at $4{ }^{\circ} \mathrm{C}$ and $90 \pm 5 \%$ $\mathrm{RH}$. Lyophilized K. radicincitans and C. laurentii were inoculated separately as a control 
radicincitans controlled $B$. cinerea better while $C$. laurentii controlled $P$. expansum more efficiently than the bacterium. The mixture of the two formulations (each containing one of the BCAs) in the same ratio showed a strong antagonism towards both phytopathogens (Mixture A, 1:1). This antagonism was affected when the bacterium was in a higher proportion than the yeast (Mixture B, 2:1), but not when it was the yeast that was in higher proportion (Mixture $C, 1: 2$ ). The presence of the yeast resulted essential for the control of $P$. expansum and to reinforce the control of $B$. cinerea. The formulation containing the mix of BCAs (LM) showed a lower antagonistic capacity, perhaps related to the decrease in the viability of the BCAs. The antagonism was improved when the concentration of the cryoprotectant was modified, and the survival of $K$. radicincitans increased. In this case, no significant differences were observed with mixture $B(2: 1)$, although the antagonistic capacity of mixtures $A$ and $C$ was not reached. The explanation could be found in the population dynamics of the lyophilized mixture (LM) where it was observed a probable decrease in the vitality of $C$. laurentii whose growth showed a delay of 3 days in comparison to K. radicincitans.

According to Hubálek [8], suitable cryoprotectants or mixtures of cryoprotectants, as well as the optimal concentration of them, must be determined empirically by trial-and-error. In theory, the formation of an amorphous, liquid, and supersaturated layer with a very high viscosity that protects the cell is postulated. Bridges are formed between the cryoprotectant and the cellular structures that would stabilize proteins by avoiding denaturation in the absence of water [10,13-15]. These authors also indicate that the cryosensitivity of each class of microorganisms may be different. When mixtures of cryoprotectants, such as carbohydrates, proteins, and polymers are used, they can interact with each other and with crucial molecules of the cell surface, producing different effects than when used individually $[8,20]$. Besides, polysaccharides isolated from yeast capsules (mannan and glucomannan) have been used as cryoprotectants but with little success [2]. The decrease in the viability of the bacterium and yeast when they were lyophilized together could be due to their different affinity for the cryoprotectant. Perhaps, the formation of bonds or bridges between each microorganism and the cryoprotectant could vary and could be affected by the presence of the other.

The hypothesis about a competition by the cryoprotectant between the bacterium and the yeast was proved by the increment of the concentration of SMYG components. The results showed a positive effect on the survival of $K$. radicincitans with the increment in the concentration of SMYG components. Survival increased by using SMYG 15 concerning SMYG 10 and SMYG 5. In particular, the viability of $K$. radicincitans increased significantly. Nevertheless, it was not a significant difference between SMYG 15 and SMYG 20, perhaps due to a saturating effect of the cryoprotectant on microorganisms. It is interesting to note that with SMYG 15, the viability of the bacteria was significantly improved and that the mixture, in this case, had similar effectiveness to the 2:1 combination (K. radicincitans: C. laurentii) for the control of phytopathogens.

\section{Conclusions}

In the present work, we demonstrate that it is possible to obtain a dry mixed formulation to apply to the postharvest control of pathogenic fungi, which would have practical advantages for its commercialization and application since two BCAs are present in a single formulation. The developed formulation, which contains the bacteria $K$. radicincitans and the yeast $C$. laurentii, showed greater effectiveness against $P$. expansum and $B$. cinerea in stored apple fruits than each microorganism individually. Although it was possible to achieve a significant reduction in the incidence of the mentioned phytopathogens, taking into account that the effectiveness of the formulation depends on an adequate BCAs activity, more work must be done to achieve higher viability and vitality of the microorganisms in the mixture. Perhaps, future works not only must be concerning the nature of cryoprotectant and the lyophilization conditions but also to the rehydration process, possibly more related to the vitality of the BCAs.

Acknowledgements The authors gratefully acknowledged support from Universidad Nacional de San Luis and INQUISAL (Conicet, San Luis)

Funding This study was funded by Universidad Nacional de San Luis through the PROICO 2-2716.

\section{Compliance with ethical standards}

Conflict of interest The authors declare that they have no conflict of interest.

\section{References}

1. Alwathnani HA, Perveen K (2012) Biological control of fusarium wilt of tomato by antagonist fungi and cyanobacteria. Afr J Biotechnol 11:1100-1105

2. Breierová E, Kocková-Kratochvílová A (1992) Cryoprotective effects of yeast extracellular polysaccharides and glycoproteins. Cryobiology 29:385-390

3. Calvo J, Calvente V, Orellano ME, Benuzzi D, Sanz MI (2010) Control of Penicillium expansum and Botrytis cinerea on apple fruit by mixtures of bacteria and yeast. Food Bioproc Technol 3:644-650 
4. Droby S, Wisniewski M, Teixidó N, Spadaro D, Jijakli MH (2016) The science, development, and commercialization of postharvest biocontrol products. Postharvest Biol Tech 122:22-29

5. FAO, IFAD, UNICEF, WFP, WHO (2018) The state of food security and nutrition in the world 2018. Building climate resilience for food security and nutrition. Rome, FAO

6. Guetsky R, Shtienberg D, Elad Y, Fischer E, Dinoor A (2002) Improving biological control by combining biocontrol agents each with several mechanisms of disease suppression. Phytopathology 92:976-985

7. Guetsky R, Elad Y, Shtienberg D, Dinoor A (2002) Improved biocontrol of Botrytis cinerea on detached strawberry leaves by adding nutritional supplements to a mixture of Pichia guilliermondii and Bacillus mycoides. Biocontrol Sci Tech 12:625-630

8. Hubálek Z (2003) Protectants used in the cryopreservation of microorganisms. Cryobiology 46:205-229

9. INDEC (2018) Instituto Nacional de Estadística y Censos. Anuario estadístico de la República Argentina 2017.-1ª ed

10. Israeli E, Shaffer BT, Lighthart B (1993) Protection of freeze-dried Escherichia coli by trehalose upon exposure to environmental conditions. Cryobiology 30:519-523

11. Janisiewicz WJ, Korsten $L$ (2002) Biological control of postharvest diseases of fruits. Annu Rev Phytopathol 40:411-441

12. Lambrese $Y$, Guiñez M, Calvente V, Sansone G, Cerutti S, Raba J, Sanz MI (2018) Production of siderophores by the bacterium Kosakonia radicincitans and its application to control of phytopathogenic fungi. Bioresour Technol Reports 3:82-87

13. Leslie SB, Israeli E, Lighthart B, Crowe JH, Crowe LM (1995) Trehalose and sucrose protect both membranes and proteins in intact bacteria during drying. Appl Environ Microbiol 61:3592-3597

14. Lodato P, De Huergo MS, Buera MP (1999) Viability and thermal stability of a strain of Saccharomyces cerevisiae freeze-dried in different sugar and polymer matrices. Appl Microbiol Biotechnol 52:215-220

15. Morgan CA, Herman N, White PA, Vesey G (2006) Preservation of microorganisms by drying; a review. J Microbiol Methods 66:183-193

16. Navarta LG, Calvo J, Posetto P, Cerutti S, Raba J, Benuzzi D, Sanz MI (2014) Postharvest control of gray mold in apples with lyophilized formulations of Cryptococcus laurentii: the effect of cold stress in the survival and effectiveness of the yeast. Food Bioproc Technol 7:2962-2968

17. Nunes CA (2012) Biological control of postharvest diseases of fruit. Eur J Plant Pathol 133:181-196
18. Panebianco S, Vitale A, Polizzi G, Scala F, Cirvilleri G (2015) Enhanced control of postharvest citrus fruit decay by means of the combined use of compatible biocontrol agents. Biol Control 84:19-27

19. Romanazzi G, Lichter A, Gabler FM, Smilanick JL (2012) Recent advances on the use of natural and safe alternatives to conventional methods to control postharvest gray mold of table grapes. Postharvest Biol Tech 63:141-147

20. Ruwart MJ, Holland JF, Haug A (1975) Fluorimetric evidence of interactions involving cryoprotectants and biomolecules. Cryobiology 12:26-33

21. Sansone G, Rezza I, Calvente V, Benuzzi D, de Tosetti MIS (2005) Control of Botrytis cinerea strains resistant to iprodione in apple with rhodotorulic acid and yeasts. Postharvest Biol and Tech 35:245-251

22. Sanzani SM, Reverberi M, Geisen R (2016) Mycotoxins in harvested fruits and vegetables: Insights in producing fungi, biological role, conducive conditions, and tools to manage postharvest contamination. Postharvest Biol Tech 122:95-105

23. Spadaro D, Gullino ML (2005) Improving the efficacy of biocontrol agents against soilborne pathogens. Crop Prot 24:601-613

24. Spadaro D, Droby S (2016) Development of biocontrol products for postharvest diseases of fruit: the importance of elucidating the mechanisms of action of yeast antagonists. Trends Food Sci Technol 47:39-49

25. Sugar D, Basile SR (2011) Orchard calcium and fungicide treatments mitigate effects of delayed postharvest fungicide applications for control of postharvest decay of pear fruit. Postharvest Biol Tech 60:52-56

26. USDA (2018) GAIN report number: date: $11 / 16 / 2018$. Argentina fresh deciduous fruit annual

27. Usall J, Ippolito A, Sisquella M, Neri F (2016) Physical treatments to control postharvest diseases of fresh fruits and vegetables. Postharvest Biol and Technol 122:30-40

28. Wisniewski M, Droby S, Norelli J, Liu J, Schena L (2016) Alternative management technologies for postharvest disease control: the journey from simplicity to complexity. Postharvest Biol Tech 122:3-10

Publisher's Note Springer Nature remains neutral with regard to jurisdictional claims in published maps and institutional affiliations. 